\section{Estudo comparativo da resistência à tração do peritônio (bovino, eqüino, suíno e canino) a fresco e conservado em glicerina}

\author{
Comparative study of resistance to tension of the \\ peritoneus (equine, swine, bovine, and canine) fresh and \\ conserved in glicerin
}

Leila Cristina BATISTA ${ }^{1}$; Carlos Roberto DALECK ${ }^{1}$; Antonio Carlos SHIMANO²; Antonio Carlos ALESSI ${ }^{3}$; Marcos de Souza ABRAHÃO

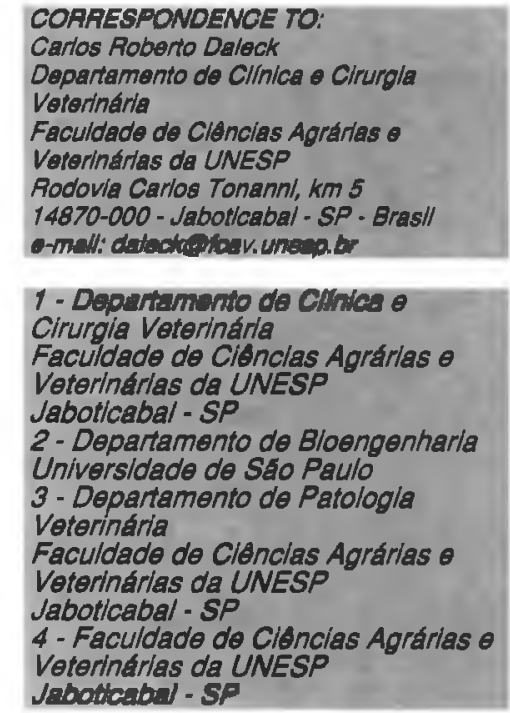

\title{
RESUMO
}

Inúmeras moléstias, tais como neoplasias, traumatismos, abscessos, nódulos parasitários, podem comprometer a função normal de um órgão. Isto torna necessária, muitas vezes, a correção cirúrgica com a utilização de implantes, entre eles, as membranas biológicas. A finalidade deste trabalho foi testar e analisar a influência da glicerina na resistência à tração e na elasticidade de peritônios de bovino, eqüino, suíno e canino, assim como estabelecer uma comparação entre as membranas das espécies citadas, e suas alterações histológicas. Para isso, após o sacrifício dos animais, foram retiradas amostras de peritônio, padronizadas para cada espécie. Foram obtidos, então, os corpos de prova, padronizados nas dimensōes de $6 \mathrm{~mm}$ de largura e $50 \mathrm{~mm}$ dé comprimento. Os ensaios de tração foram realizados em corpos de prova a fresco e em outros mantidos em glicerina durante 15, 30 e 60 dias. Os testes foram realizados em Máquina Universal de Ensaio. Após o teste mecânico de tração, os corpos de prova foram fixados, e cortes histológicos, corados pelo método de Hematoxilina-Eosina, foram obtidos e analisados. Os resultados da tração do peritônio a fresco bovino, eqüino, suíno e canino, quando analisados os alongamentos em função das cargas aplicadas, mostraram comportamentos heterogêneos, e o ponto de ruptura das membranas foi bastante diferente entre as espécies.

UNITERMOS: Peritônio; Cães; Cavalos; Porcos; Bovinos.

\section{INTRODUÇĀO}

$\mathrm{D}$ esde a década de 60 temos conhecimento, em nosso meio, da utilização de membranas biológicas como material de implante, com o trabalho de Pigossi ${ }^{5}$ (1967) utilizando dura-máter homóloga, conservada em glicerina, em cães. A utilização de membranas biológicas devese, principalmente, à facilidade de obtenção, baixo custo, preparo simples, esterilização viável, facilidade de estocagem e utilização e mínima reação tecidual (Alvarenga ${ }^{2}, 1993$ ).

A principal finalidade da utilização de membranas biológicas, obtidas de diferentes espécies animais, assim como dos implantes sintéticos, é fornecer arcabouço para orientação e desenvolvimento de novo tecido, à custa de processos de reparação, restabelecendo a estrutura e a função do órgão afetado. Estas membranas podem ser obtidas de diferentes espécies animais.

Como principal meio de conservação dessas membranas, utiliza-se a glicerina a $98 \%$, mantida em temperatura ambiente. A glicerina apresenta as vantagens de ser de baixo custo e, principalmente, por não requerer baixa temperatura, dispensando meios de conservação de custo elevado e de difícil transporte. Vários autores utilizaram a glicerina a $98 \%$ para conservação das membranas biológicas (Pigossi ${ }^{5}, 1967$; Alvarenga ${ }^{1}$, 1977; Barros et al. ${ }^{3}$, 1980; Daleck ${ }^{4}, 1986$; Ranzani' ${ }^{6}$, 1986).

Os ensaios biomecânicos têm por objetivo determinar as propriedades mecânicas do material estudado. Dependendo das características físicas do material, podemos submetê-lo a ensaios de tração, torção, compressão e flexão. $\mathrm{O}$ osso está 
BATISTA, L.C.; DALECK, C.R.; SHIMANO, A.C.; ALESSI, A.C.; ABRAHÃO, M.S. Estudo comparativo da resistência à tração do peritônio (bovino, eqüino, suíno e canino) a fresco e conservado em glicerina. Braz. J. vet. Res. anim. Sci. São Paulo, v.33, supl., p.305-312, 1996.

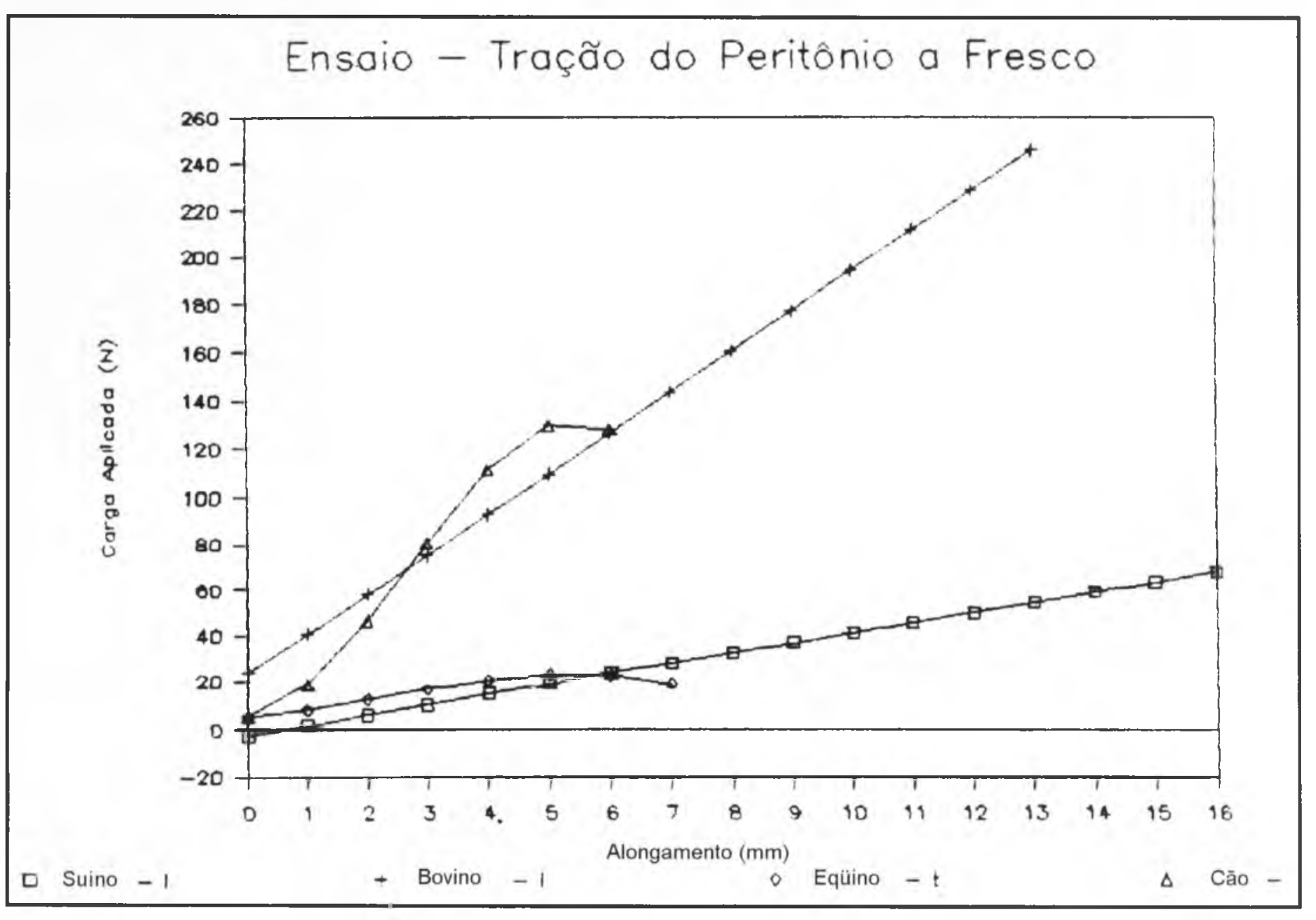

Figura 1

Ensaio de tração dos peritônios de bovino, suíno, eqüino e cão a fresco.

entre os materiais biológicos mais freqüentemente submetidos a ensaios biomecânicos. Em uma outra situaçāo Pigossi ${ }^{5}$ (1967) avaliou a resistência à tração e alongamento até a ruptura, da dura-máter de cão conservada em glicerina.

Reyes $^{7}$ (1993) realizou testes físicos comparativos de membranas biológicas preservadas em glicerina, congeladas e a fresco. Concluiu que o pericárdio eqüino, em glicerina a $98 \%$ à temperatura ambiente por 30 ou 40 dias, aumenta significativamente os valores dos alongamentos até a rotura, quando se comparam estes resultados com preparaçōes não preservadas. Os mesmos resultados foram obtidos com fascia lata de eqüino em glicerina a $98 \%$ e congeladas a menos $16^{\circ} \mathrm{C}$ por período de 30 e 40 dias.

O presente trabalho tem por objetivo testar e analisar a influência da glicerina na resistência à traçāo e na elasticidade do peritônio de bovino, eqüino, suíno e canino, assim como estabelecer comparaçāo entre as membranas das espécies acima citadas, e suas possíveis alterações histológicas.

\section{MATERIAL E MÉTODO}

\section{Peritônio}

Foram utilizados peritônios de bovinos, eqüinos, suínos e caninos saudáveis, colhidos logo após o sacrifício dos animais em abatedouros ou no Hospital Veterinário da FCAV-UNESP. Após a colheita, as amostras de peritônio foram devidamente lavadas em água corrente para a retirada de resíduos. As amostras a fresco foram mantidas em soluçāo fisiológica durante o período gasto para o transporte até o Laboratório de testes. As demais amostras foram imersas em glicerina a $98 \%$.

\section{Glicerina}

Foi utilizada a glicerina a $98 \%$, mantida a temperatura ambiente, como meio de conservaçāo. Foram utilizados frascos de boca larga com uma proporção de glicerina: peritônio superior a 20:1. 


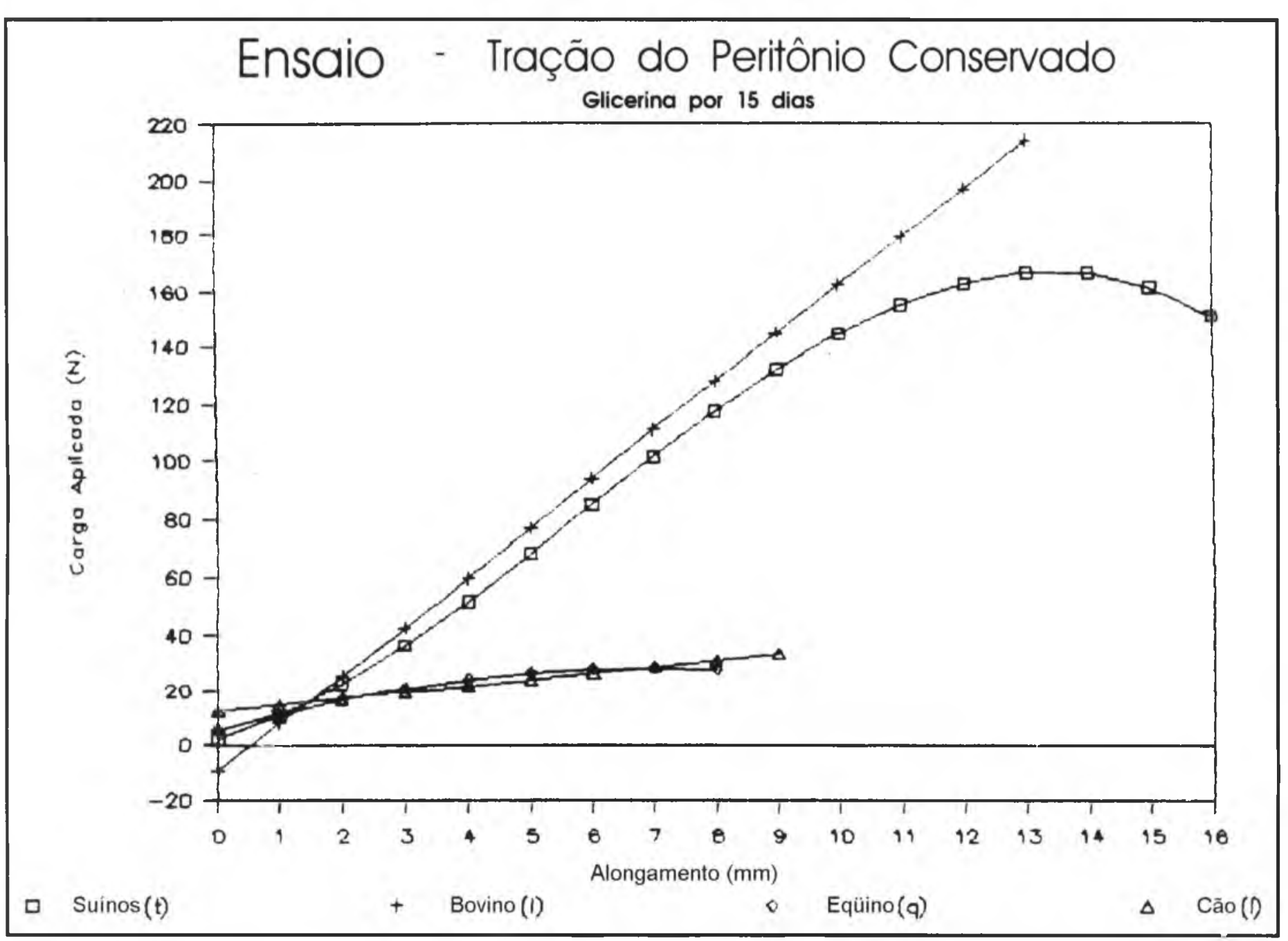

Figura 2

Ensaio de traçāo dos peritônios de bovino, suíno, eqüino e cāo, conservados em glicerina por 15 dias

\section{Corpos de prova}

Os corpos de prova foram padronizados nas dimensões de 6 $\mathrm{mm}$ de largura e $50 \mathrm{~mm}$ de comprimento, baseando-se na pequena amostra de peritônio de cão que é obtida.

Os ensaios de tração foram realizados em corpos de prova a fresco e conservados em glicerina durante 15,30 e 60 dias.

\section{Bioensaio mecânico de tração}

Os testes foram realizados em Máquina Universal de Ensaio do Laboratório de Bioengenharia da Faculdade de Medicina de Ribeirão Preto-USP. A leitura da carga foi feita por célula de carga de capacidade de até 2000 Newton (N). A máquina tem sistemas de controle da velocidade de aplicaçāo da carga e de inversor para mudar o sentido da rotação do motor. $O$ conjunto foi preparado para a realização de testes de tração, a partir da troca das conexões e acessórios.
O registro das informações obtidas na máquina de ensaio foi realizado por um Sistema Modular de Extensiometria Série 200 .

O módulo de leitura é constituído por um voltímetro digital de 4 dígitos, que permite leituras de até 10 ensaios diferentes, selecionados por uma chave comutadora.

A fixação foi feita por cilindros que contêm em sua superfície, ranhuras que auxiliam na fixaçāo dos corpos de prova através de compressão feita por um parafuso. Na fixação dos corpos de prova foi necessária a verificação da carga inicial aplicada para que os mesmos tivessem uma padronização. Tomou-se o cuidado de deixar o comprimento livre de $30 \mathrm{~mm}$ entre as extremidades das garras. Após a fixação, foi dada uma pré-carga de $6 \mathrm{kgf}$ por aproximadamente 60 segundos, para que houvesse acomodação do sistema. A velocidade de aplicação da carga foi de aproximadamente $6 \mathrm{~mm} / \mathrm{s}$.

A medida do alongamento foi feita por escala milimétrica colocada paralelamente ao eixo de traçāo do corpo de prova. 


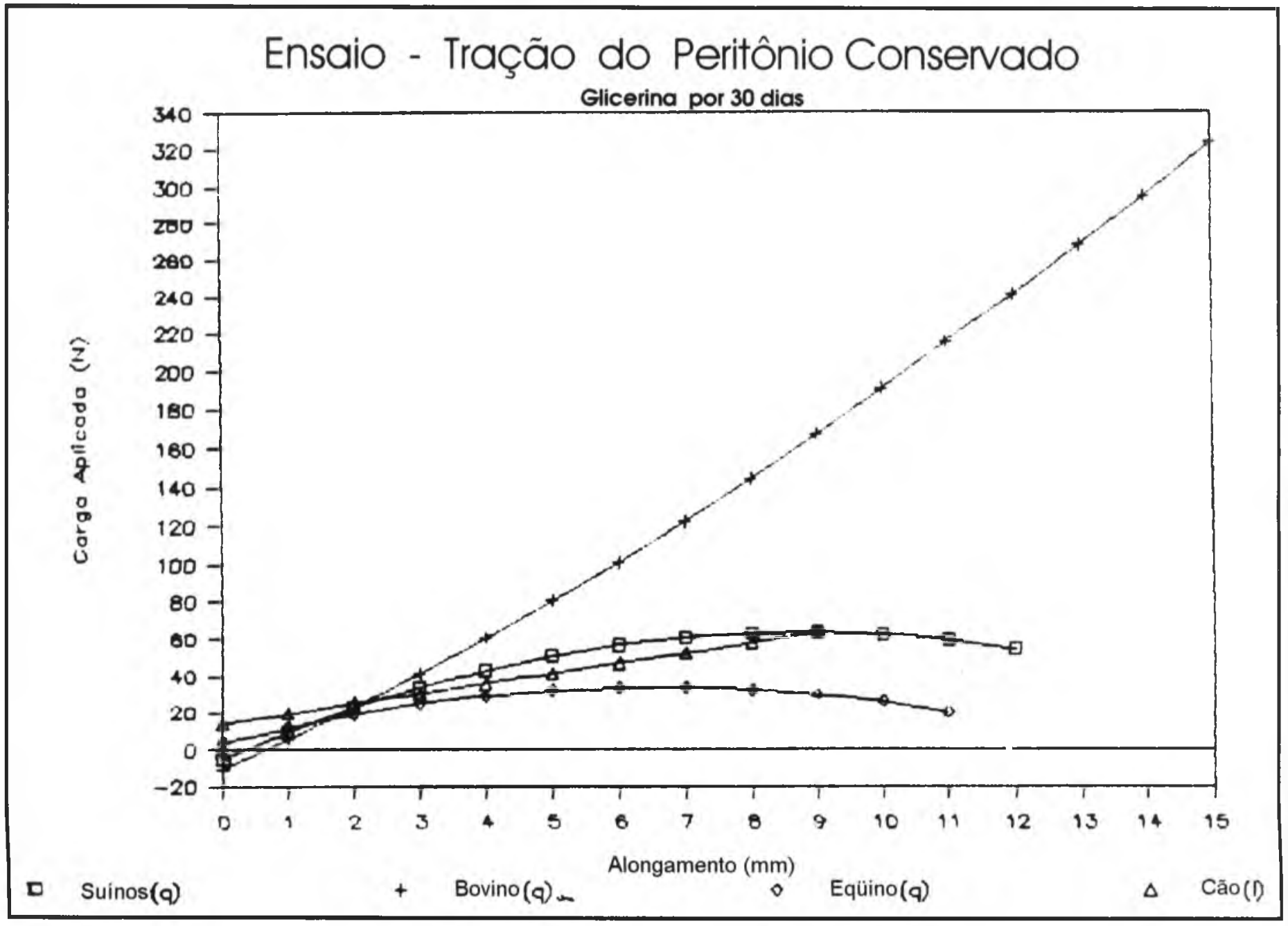

Figura 3

Ensalo de tração dos peritônios de bovino, suíno, eqüino e cão, conservados em glicerina por 30 dias.

\section{Delineamento experimental}

O grupo experimental constituiu-se de animais da espécie canina, bovina, eqüina e suína, e, de cada espécie, foram retiradas amostras de peritônio e, a partir destas, obtidos três corpos de prova para cada espécie.

\section{Análise estatística}

Para estudo da relação entre a carga aplicada e o alongamento do peritônio, utilizou-se a regressão polinomial até $3^{\underline{Q}}$ grau, de acordo com o resultado dos polinômios ortogonais.

\section{Técnicas histológicas}

Após o ensaio mecânico de tração, os corpos de prova foram fixados em solução tamponada de formalina a $10 \%$, desidratados e incluídos em parafina. Cortes histológicos de 5 micrômetros de espessura foram obtidos e corados pelo método de Hematoxilina-Eosina (HE).

\section{RESULTADOS E DISCUSSÃO}

A Fig. 1 mostra a extensão do alongamento dos peritônios a fresco de bovino, canino, suíno e eqüino em função da carga aplicada. Observa-se que para um alongamento de $6 \mathrm{~mm} \mathrm{o}$ peritônio de bovino necessitou de carga de $70 \mathrm{~N}$. O de canino necessitou de uma carga de $120 \mathrm{~N}$, seguido dos peritônios de eqüino e de suíno, que necessitaram carga de $20 \mathrm{~N}$.

Após 15 dias de conservação em glicerina, o peritônio de bovino necessitou de uma carga de $215 \mathrm{~N}$ para $12 \mathrm{~mm}$ de alongamento; o de suíno teve a resistência aumentada, necessitando de uma carga de $170 \mathrm{~N}$ para $13 \mathrm{~mm}$ de alongamento; e o de cão, semelhante ao de eqüino, de uma carga de $20 \mathrm{~N}$ para o alongamento de $6 \mathrm{~mm}$ (Fig. 2).

A tração do peritônio conservado em glicerina por 30 dias 


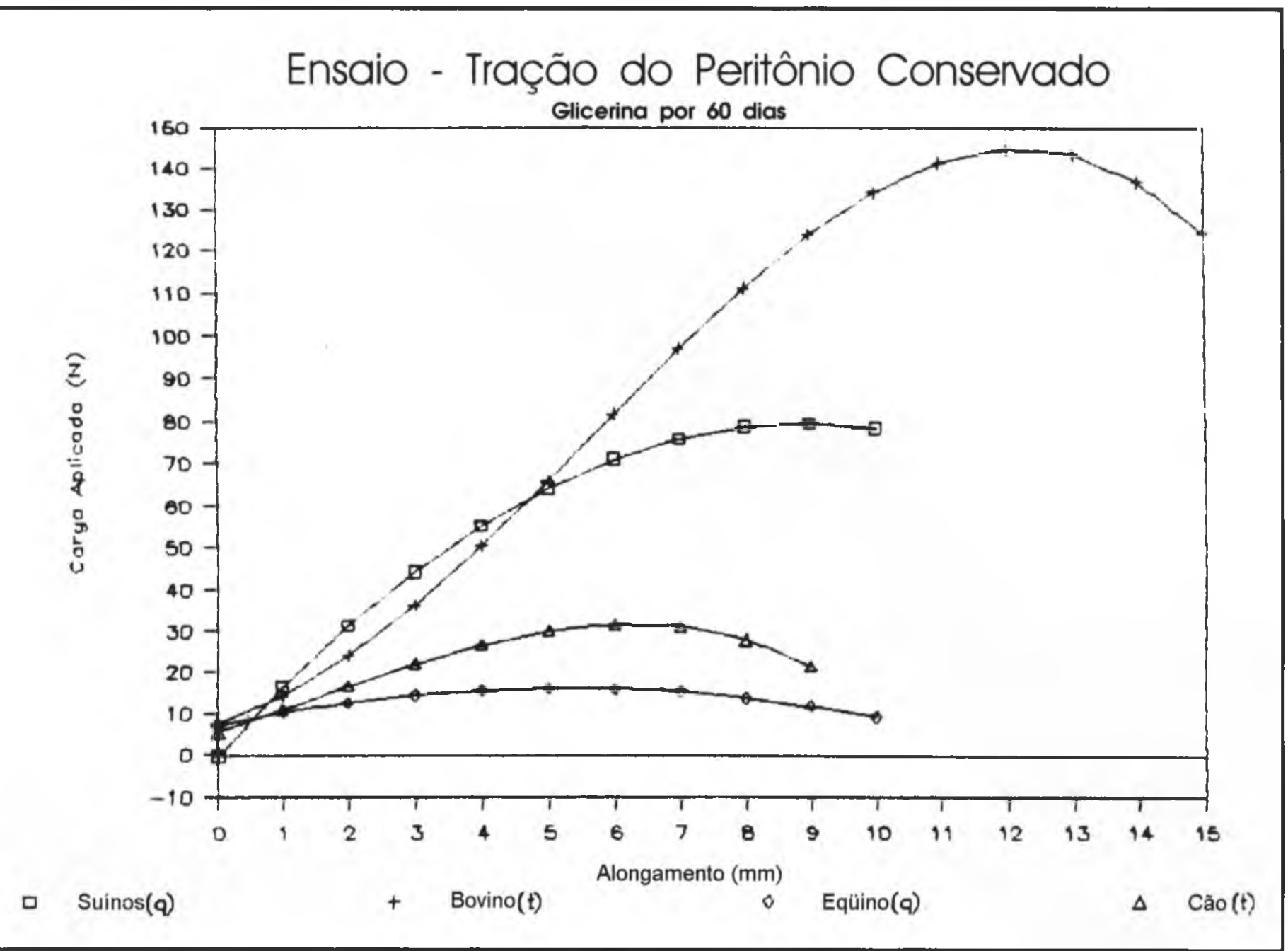

Figura 4

Ensaio de tração dos peritônios de bovino, suíno, eqüino e cão, conservados em glicerina por 60 dias.

mostrou queda de resistência para a membrana do suíno e aumento da mesma para a membrana do cão, enquanto as outras membranas mostraram comportamentos semelhantes aos anteriormente apresentados (Fig. 3).

A Fig. 4 mostra queda da resistência para a membrana do cão, enquanto o peritônio de suíno sofreu aumento da resistência. As membranas de eqüino e bovino mantiveram o mesmo padrão de comportamento.

A Tab. 1 mostra a análise estatística das amostras dos peritônios de suíno, bovino, eqüino e cão, a fresco e com 15 , 30 e 60 dias de conservação em glicerina, em que se observaram as reaçōes lineares, 05 reaçōes quadráticas e 06 reações cúbicas.

A tração do peritônio de bovino, canino, suíno e eqüino a fresco mostrou, quando analisados os alongamentos em função as cargas aplicadas, comportamentos diferentes (Fig, 1). O ponto de ruptura das membranas biológicas foi bastante diferente entre as espécies. Assim, o peritônio de bovino necessitou de carga de $250 \mathrm{~N}$ para produzir alongamento máximo de $13 \mathrm{~mm}$, o de suíno de carga de $70 \mathrm{~N}$ para alongamento de $16 \mathrm{~mm}$, para o peritônio de cão houve necessidade de carga de $120 \mathrm{~N}$ para alongamento de $6 \mathrm{~mm}$ e para o de eqüino carga de $20 \mathrm{~N}$ para $6 \mathrm{~mm}$ de alongamento. Tomando-se o valor de $6 \mathrm{~mm}$ de alongamento para todas as espécies, nota-se diferença acentuada de carga aplicada para o peritônio de bovino e de cão $(120 \mathrm{~N})$ e para o de suíno e de eqüino $(20 \mathrm{~N})$. Apesar da semelhança de carga aplicada para este valor de alongamento $(6 \mathrm{~mm})$ entre o peritônio bovino e o de cão, torna-se necessário destacar que o ponto de ruptura das membranas é bastante diferente mostrando que o peritônio do bovino é mais resistente que o do cão. A mesma observação deve ser feita em relação ao do suíno e do eqüino.

O peritônio do cão conservado sofreu queda na sua tração quando comparado com o a fresco. Os peritônios de bovino e de equiino, no entanto, mantiveram suas resistências à tração quando analisados a fresco ou conservados. Entretanto, Reyes ${ }^{7}$ (1993) concluiu em seu experimento que o pericárdio e a fascia lata de eqüino, quando conservados em glicerina a $98 \%$ e à

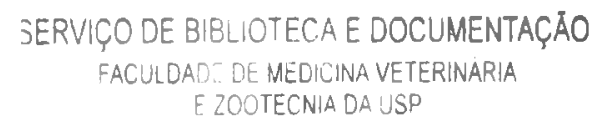

309 
BATISTA. L.C.: DALECK. C.R.: SHIMANO, A.C.: ALESSI. A.C.; ABRAHĀO, M.S. Estudo comparativo da resistêncià à traçĩo do peritônio (bovino, eqüino, suíno e canino) a fresco e conservado em glicerina. Braz. J. vet. Res. anim. Sei. São Paulo, v. 33, supl., p.305-312, 1996.

\section{Tabela 1}

Avaliaçāo da resistência à tração dos peritônios de suíno, bovino. eqüino e cāo, a fresco e com 15, 30 e 60 dias de conservação em glicerina. Estão representadas as análises estatísticas (Teste F) e a equação correspondente Jaboticabal - SP, 1995.

\begin{tabular}{|c|c|c|c|c|c|c|c|}
\hline \multirow{2}{*}{\multicolumn{2}{|c|}{ Animal }} & \multicolumn{4}{|c|}{ Teste F } & \multirow[t]{2}{*}{$\mathrm{R}^{2}$} & \multirow[t]{2}{*}{ Equação } \\
\hline & & R.L. & R.Q. & R.C. & D.R. & & \\
\hline \multirow{4}{*}{ Fresco } & Suino & $77,04^{\star \star}$ & $3,43^{\mathrm{NS}}$ & $0,03^{N S}$ & $0,17^{\mathrm{NS}}$ & 0,9314 & $y=-2.6536+4.4138 x$ \\
\hline & Bovino & $139,66^{\star \star}$ & $3,11^{\mathrm{NS}}$ & $3,12^{\text {NS }}$ & $0,95^{\mathrm{NS}}$ & 0,8989 & $y=23,8476+17,0674 x$ \\
\hline & Cāo & $197,99 \star \star$ & $2,63^{\mathrm{NS}}$ & $6,04^{\star}$ & $0,05^{\mathrm{NS}}$ & 0,9993 & $y=5,6349+3,2884+11,6190 x^{2}-1,4630 x^{3}$ \\
\hline & Eqüino & $234,84^{\star \star}$ & $46,05^{\star \star}$ & $12,14^{\star \star}$ & $1,62^{\mathrm{NS}}$ & 0,9783 & $y=5,3283+2,1865+1,0187 x^{2}-0,1490 x^{3}$ \\
\hline \multirow{4}{*}{15 dias } & Suíno & $360,57^{\star \star}$ & $21,34^{\star \star}$ & $8,71^{\star \star}$ & $0,33^{\mathrm{NS}}$ & 0,9891 & $y=1,9553+7,2911+1,6594 x^{2}-0,0956 x^{3}$ \\
\hline & Bovino & $414,69^{\star \star}$ & $0,13^{\text {NS }}$ & $3,03^{N S}$ & $0,35^{\mathrm{NS}}$ & 0,9842 & $y=-9,1809+17,1744 x$ \\
\hline & Cão & $5,85^{\star}$ & $2,41^{\mathrm{NS}}$ & $0,23^{N S}$ & $0,04^{\mathrm{NS}}$ & 0,6696 & $y=12,6606+2,2606 x$ \\
\hline & Eqüino & $111,82^{\star \star}$ & $16,37^{\star}$ & $0,02^{N S}$ & $0,38^{\mathrm{NS}}$ & 0,9850 & $y=5,5232+6,4785-0,4654 x^{2}$ \\
\hline \multirow{4}{*}{30 dias } & Suíno & $45,86^{\star \star}$ & $16,42^{\star \star}$ & $3,29^{N S}$ & $0,16^{\mathrm{NS}}$ & 0,9293 & $y=-4,9157+15,5630 x-0,8872 x^{2}$ \\
\hline & Bovino & $1062,32^{\star \star}$ & $6,23^{\star}$ & $2,96^{\mathrm{NS}}$ & $0,69^{\mathrm{NS}}$ & 0,9895 & $y=-10,5890+16,0476 x+0,4164 x^{2}$ \\
\hline & Cāo & $15,79^{\star \star}$ & $2,79^{\mathrm{NS}}$ & $0,07^{\mathrm{NS}}$ & $0,03^{N S}$ & 0,8376 & $y=14,2485+5,4040 x$ \\
\hline & Eqüino & $8,30^{\star}$ & $15,73^{\star \star}$ & $0,01^{\mathrm{NS}}$ & $0,07^{\mathrm{NS}}$ & 0,9774 & $y=3,9446+8,9881-0,6799 x^{2}$ \\
\hline \multirow{4}{*}{60 dias } & Suíno & $61,13^{\star \star}$ & $7,75^{\star}$ & $2,84^{\mathrm{NS}}$ & $0,04^{\mathrm{NS}}$ & 0,9566 & $y=-0,3566+17,8701 x-1,0015 x^{2}$ \\
\hline & Bovino & $110,78^{\star \star}$ & $8,71^{\star \star}$ & $4,16^{\star}$ & $0,69^{N S}$ & 0,9375 & $y=7,6580+4,7161 x+1,9714 x^{2}-0,1178 x^{3}$ \\
\hline & Cäo & $97,34^{\star \star}$ & $68,48^{\star \star}$ & $4,41^{\star}$ & $1,38^{\mathrm{NS}}$ & 0,9536 & $y=5,5558+5,2841 x+0,3067 x^{2}-0,0772 x^{3}$ \\
\hline & Eqüino & $1,91^{\mathrm{NS}}$ & $36,77^{\star \star}$ & $2,14^{\mathrm{NS}}$ & $0,62^{N S}$ & 0,8560 & $y=7,2611+3,3358 x-0,3164 x^{2}$ \\
\hline
\end{tabular}

R.L. $=$

R.Q. $=$

R.C. $=$

$\mathrm{DR} .=$

temperatura ambiente por 30 e 40 dias, aumentam significativamente os valores dos alongamentos até a rotura, quando se comparam estes resultados com preparações nāo preservadas.

Analisando o comportamento da membraria biológica do suíno, quando conservada em glicerina a $98 \%$, verificou-se uma oscilação entre aumento e diminuição da resistência, atribuíveis talvez à não uniformidade no local da colheita, uma vez que os fragmentos, embora contíguos, não eram os mesmos.

Histologicamente, observou-se que o material a fresco tende a se corar melhor pela técnica da HE ou, por outro lado, que o tecido conservado em glicerina torna-se menos afim aos corantes, resultando em cortes pouco corados. Observou-se também que o peritônio a fresco mantém suas fibras e células mais unidas (Fig. 5-A e 5-B), ao passo que os conservados em glicerina mostram seus componentes mais dissociados (Fig. 5C e 5-D), e estes aspectos foram independentes do tempo de conservaçāo das membranas na glicerina, ou seja, não existiu diferença aparente entre 15,30 ou 60 dias.

Quanto aos aspectos histológicos dos peritônios dos animais das quatro espécies estudadas, observou-se que há
NS = nāo significativo

* $=$

$\star \star *$

bastante semelhança entre eles.

Verificou-se ainda que o local da ruptura do peritônio, quando detectado no corte histológico, indicava que o processo parecia iniciar-se pelo tecido conjuntivo que acompanha as células mesoteliais. Outras vezes, a camada mesotelial também apresentava descontinuidade (Fig. 5-B).

A Fig. 5-B mostra também que o peritônio de cāo conservou fragmentos maiores após ruptura. Por outro lado, no peritônio de eqüino houve maior dissociação e fragmentaçāo das camadas de fibras (Fig. 5-D).

$\mathrm{O}$ freqüente emprego de membranas biológicas, em cirurgia, por vários autores (Pigossi', 1967; Alvarenga', 1977; Barros et al. ${ }^{3}, 1980$; Daleck ${ }^{4}, 1986$; Ranzani $\left.{ }^{6}, 1986\right)$ justificou a procura de um bioensaio mecânico de tração que pudesse mostrar variações na resistência de membranas biológicas. Ensaios dessa natureza poderão ser aplicados em um grande número de diferentes membranas de diferentes espécies animais. Permitem ainda verificar meios e tempos de conservaçāo, antes dos ensaios "in vivo".

A conservação em glicerina a $98 \%$, técnica que pode ser utilizada amplamente em Clínicas Veterinárias, mostrou-se adequada por não comprometer a resistência do material 
BATISTA. L.C.; DALECK, C.R.; SHIMANO, A.C.: ALESSI, A.C.; ABRAHĀO, M.S. Estudo comparativo da resistência à traçāo do peritônio (bovino, eqüino, suíno e canino) a fresco e conservado em glicerina. Braz. J. vet. Res. anim. Sci. São Paulo, v.33, supl., p.305-312, 1996.

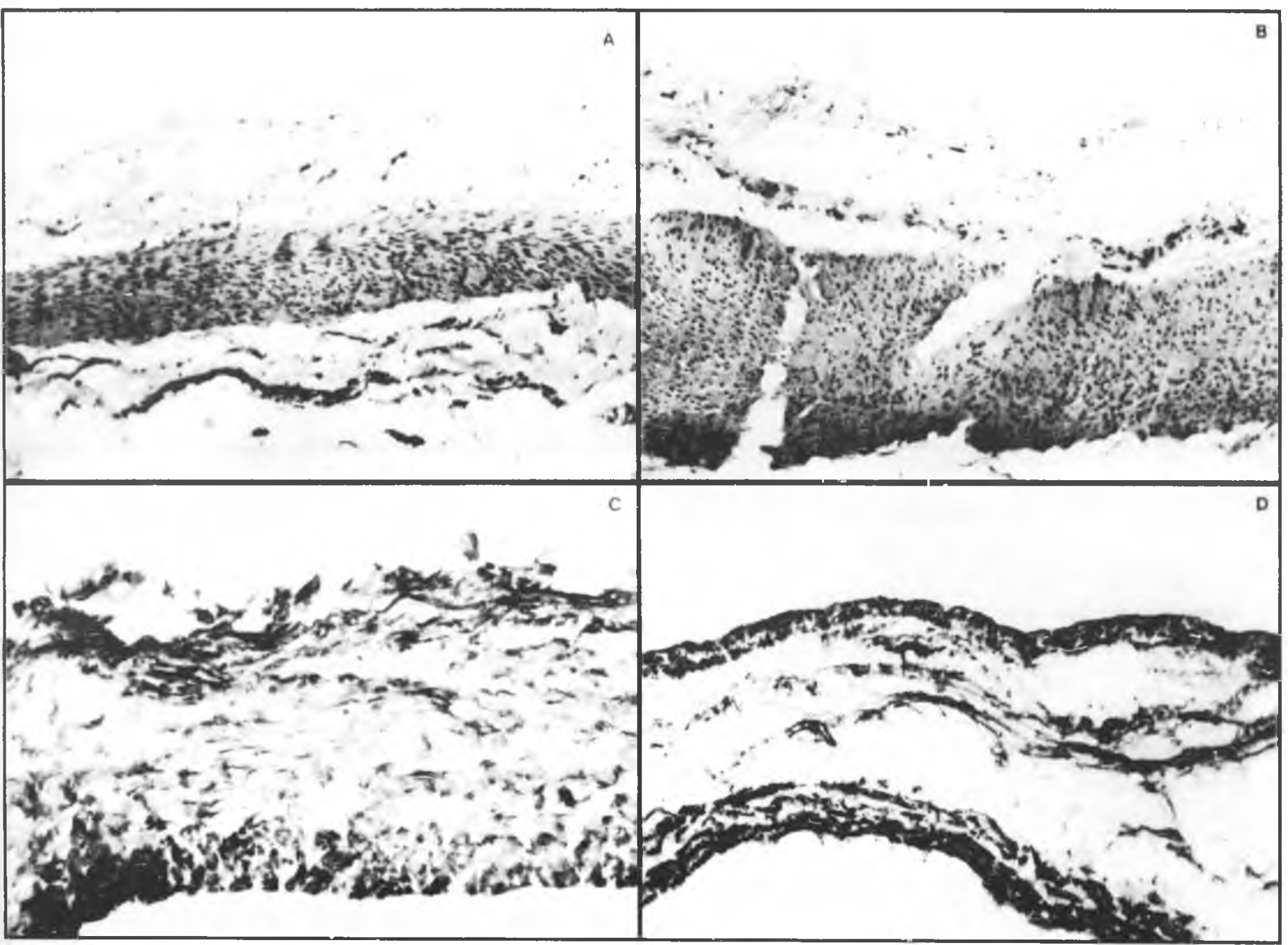

Aspecto histológico do peritônio:

Figura 5

A. Peritônio bovino a fresco. As fibras e as células aparecem mais unidas. Obj. $12.5 x$.

B. Peritônio de cāo a fresco. Notar ruptura das camadas de tecido conjuntivo e de células mesoteliais. Obj. 12,5x

C. Peritônio de suíno conservado em glicerina por 15 dias. As fibras e células aparecem mais dissociadas. Obj. $15 x$

D. Peritônio de eqüino conservado em glicerina por 60 dias. Notar grande dissociação e fragmentaçāo das camadas de fibras

analisado. A análise da Tab. 1 permite constatar que não houve diferença significativa ao se comparar os efeitos da preservaçāo com os a fresco. Da mesma forma, o acompanhamento histológico permitiu verificar a integridade das fibras e das células mesoteliais após os diferentes períodos de conservação na glicerina. Mostrou ainda maior dissociação das fibras do peritônio conservado em glicerina, quando comparado a fresco, deixando a hipótese de que a resistência talvez seja mais ligada à membrana basal e às células mesoteliais. Isso porque em pelo menos duas espécies a conservação não alterou a resistência. Reforça ainda essa hipótese a constatação de que no peritônio de eqüino a dissociação foi ainda maior.
Essas observações e ainda a proposta de um método biomecânico para avaliaçāo de resistência de membranas biológicas justificam o presente trabalho.

\section{CONCLUSÕES}

O peritônio de bovino a fresco mostrou-se mais resistente do que o do eqüino, suíno e canino, considerando-se a força de tração e o alongamento necessário para ruptura. A conservação em glicerina por até 60 dias nāo altera significativamente a resistência do peritônio. 
BATISTA, L.C.; DALECK, C.R.; SHIMANO, A.C.; ALESSI, A.C.; ABRAHẢO, M.S. Estudo comparativo da resistência à tração do peritônio (bovino, eqüino, suíno e canino) a fresco e conservado em glicerina. Braz. J. vet. Res. anim. Sci. São Paulo, v.33, supl., p.305-312, 1996.

\section{SUMMARY}

Several factors such as neoplasia, trauma, abscess and parasitic nodules can impair normal function of the organs. When it happens, it is often necessary to perform a surgical correction using implants made of biological membranes or synthetic material. Our objectives were to evaluate how glycerin $98 \%$ can influence the resistance and elasticity of equine, swine, bovine and canine peritoneus to be used as implants, and to determine the nature of their histological structures. Standard pieces, $6 \mathrm{~mm}$ width $-50 \mathrm{~mm}$ lenght, both fresh and glycerinated for 15, 30 and 60 days were submitted to the ratio of maximum strength. Tests were carried out using Universal Assay Machine. Right after the strength tests, the membrane pieces were fixed in formaline and processed for histological examination after hematoxylin-eosin staining. Considering the stretching range caused by traction, data showed that the different membranes did not present the same resistance, and rupture points among the 4 samples were also different.

UNITERMS: Peritoneum; Dogs; Horses; Pigs; Bovidae.

\section{REFERÊNCIAS BIBLIOGRÁFICAS}

1-ALVARENGA, J. Substituição de segmento de colédoco de cão por preparado de perićrdio homólogo conservado em glicerina. Sāo Paulo, 1977. 108p. Tese (Livre-Docência) - Faculdade de Medicina Veterinária e Zootecnia,

Universidade de São Paulo.

2-ALVARENGA. J. Possibilidades e limitações da utilização de membranas biológicas preservadas em cirurgia. In: DALECK, C.R.; BAPTISTA, L.C.; MUKAI, L. T6́picos de cirurgia de cães e gatos. Jaboticabal. FUNEP, 1993. $113 \mathrm{p}$.

3-BARROS, P.S.M.; ALVARENGA, J.; STOPIGLIA, A.L.; BORELLI, V.; GUERRA. J.L. Reparação cirúrgica da "pars muscularis" do diafragma do cão por implante de centro frênico de eqüino conservado em glicerina. In: CONFERÊNCIA ANUAL DA SOCIEDADE PAULISTA DE MEDICINA VETERINÁRIA. 35., Sāo Paulo, 1980. Resumos. São Paulo, SPMV, 1980. p. 17 .

4-DALECK, C.R. Esofagoplastia cervical no cão com peritônio autólogo ou homólogo conservado em glicerina: Estudo Experimental. Botucatu, 1986. 48p. Tese (Doutorado) - Faculdade de Medicina Veterinária e Zootecnia, Universidade Estadual Paulista.

5-PIGOSSI, N. A glicerina na conservação de dura-máter: Estudo Experimental. São Paulo, 1967.83p. Tese (Livre-Docência) - Faculdade de Medicina. Universidade de São Paulo.

6-RANZANI, J.J.T. Substituição de segmento da porçăo muscular diafragmática de cão por pericárdio de eqüino conservado em glicerina: Estudo Experimental. Botucatu, SP, 1986.57p. Tese (Doutorado) - Faculdade de Medicina Veterinária e Zootecnia, Universidade Estadual Paulista.

7-REYES, E.E.F. Testes físicos comparativos de membranas biológicas preservadas em glicerina, congeladas e a fresco. São Paulo, 1993. 85p. Tese (Mestrado) - Faculdade de Medicina Veterinária e Zootecnia, Universidade de São Paulo. 